\title{
Regulation of gene transcription by fatty acids
}

\author{
A. M. Salter ${ }^{\dagger}$ and E. J. Tarling \\ Division of Nutritional Sciences, School of Biosciences, University of Nottingham, Sutton Bonington Campus, Loughborough DE74 2FW, UK
}

(Received 20 June 2007; Accepted 12 July 2007)

\begin{abstract}
Dietary fat is well recognised as an important macronutrient that has major effects on growth, development and health of all animals including humans. The amount and type of fat in the diet impacts on many aspects of metabolism including lipoprotein pathways, lipid synthesis and oxidation, adipocyte differentiation and cholesterol metabolism. It has become increasingly apparent that many of these effects may be due to direct modulation of expression of key genes through the interaction of fatty acids with certain transcription factors. Peroxisome proliferator-activated receptors (PPARs), the liver $X$ receptors (LXRs), hepatic nuclear factor 4 (HNF-4) and sterol regulatory binding proteins (SREBPS) represent four such factors. This review focuses on emerging evidence that the activity of these transcription factors are regulated by fatty acids and the interactions between them may be responsible for many of the effects of fatty acids on metabolism and the development of chronic disease.
\end{abstract}

Keywords: gene expression, genes, lipids, transcription factors

\section{Introduction}

Dietary lipids have the capacity to regulate many aspects of metabolism in a manner dependent on chain length and the number, position and geometry of the double bonds within the fatty acids they contain. One of the most profound examples of such regulation is the impact of dietary fat on cholesterol and lipoprotein metabolism (Katan et al., 1994). It is well established that diets rich in saturated fatty acids are associated with elevated plasma concentrations of lowdensity lipoprotein (LDL) cholesterol. By contrast, enriching the diet with $n-6$ polyunsaturated fatty acids (PUFA) reduces LDL cholesterol. PUFA also have a major impact on the activity of enzymes associated with carbohydrate metabolism and lipid biosynthesis and oxidation (Sampath and Ntambi, 2005). The role of fatty acids as substrates in these pathways and their conversion to eicosanoids, with different levels of activity depending on the structure of the parent molecule, represents two mechanisms whereby they exert their effect. However, the last decade has seen a growing body of evidence to suggest that fatty acids and/or their derivatives also have direct effects on the expression of genes for proteins regulating carbohydrate and lipid metabolism (Jump and Clarke, 1999; Pégorier et al., 2004; Jump et al., 2005; Sampath and Ntambi, 2005; Davidson, 2006). This review will explore the emerging mechanisms whereby dietary fatty acids can directly influence gene expression.

\footnotetext{
${ }^{\dagger}$ Email: andrew.salter@nottingham.ac.uk
}

\section{Fatty acids and gene transcription}

Dietary long-chain fatty acids enter the blood stream primarily as components of chylomicron triacylglycerol. The bulk of these will be released by the action of lipoprotein lipase in the capillaries of tissues such as adipose tissue and muscle, and will then be transported into cells either by passive diffusion or via transporter-mediated uptake (Kalant and Ciaflone, 2004). A significant portion of chylomicron triacylglycerol, together with phospholipid and cholesterol ester, will remain with the chylomicron remnant and be removed from the circulation by the liver. The fatty acids associated with these lipids will then be released during lysosomal degradation of the lipoprotein particles. Within the cell the bulk of these fatty acids will be converted into fatty acyl-CoA derivatives and channelled into various metabolic pathways. While it is clear that the bulk of such fatty acids are either esterified or oxidised (Jump and Clarke, 1999), there is growing evidence that fatty acids or their derivatives can accumulate in different intracellular compartments. For example, specific fatty acid binding proteins have been shown to transport fatty acids, or their derivatives, directly to the nucleus (Wolfrum et al., 2001). Changes in the size and composition of these pools of fatty acids may regulate gene expression by modulating transcriptional and post-transcriptional events. In particular, much recent research has focused on the impact of fatty acids and their derivatives on the activity or abundance of specific transcription factors involved in regulating the 
expression of genes for key enzymes, receptors and transport proteins (Sampath and Ntambi, 2005; Deckelbaum et al., 2006).

\section{Molecular mechanisms involved in fatty acid regulation of gene expression}

There are at least four transcription factor families that play a major role in the fatty acid-induced regulation of gene transcription. These include peroxisome proliferator-activated receptors (PPARs), liver $X$ receptor (LXR), hepatocyte nuclear factor 4 (HNF-4) and sterol regulatory binding proteins (SREBPS). All of these, except SREBP, are members of the nuclear hormone receptor superfamily of transcription factors.

\section{Nuclear receptors}

Nuclear receptors are a class of ligand-activated intracellular transcription factors which up- or downregulate the expression of genes. Approximately 50 such receptors have been identified in humans (Robinson-Rechavi et al., 2001). A subset of these, including PPAR and LXR, bind to specific motifs (response elements) within the promoters of genes as heterodimers with the retinoid $X$ receptor (RXR). These response elements consist of direct repeats of nucleotide sequences separated by one or more nucleotides. It is now believed that these heterodimers can bind to response elements in the absence of ligand and may actually inhibit gene transcription through association with co-repressors. Ligand binding appears to initiate conformational changes which displace co-repressors and facilitate interaction with co-activators (Glass and Rosenfeld, 2000). Through a reorganisation of the chromatin and modification or recruitment of a range of factors involved in gene expression this leads to activation of transcription. Figure 1 illustrates the potential regulation of gene expression by LXR.

\section{Peroxisome proliferator-activated receptors}

PPARs are the most extensively characterised nuclear receptors that are regulated by fatty acids (Desvergne and Wahli, 1999). There are three isoforms, PPAR $\alpha$, PPAR $\beta$ (also known as $\delta$ ) and PPAR $\gamma$. PPAR $\alpha$ is expressed in liver, intestine and kidney. PPAR $\gamma$ (subforms $\gamma 1, \gamma 2$ and $\gamma 3$ arising from alternative splicing of one gene) is mainly expressed in adipose tissue and macrophages, while PPAR $\beta$ is ubiquitously expressed.

PPARs were initially identified for their capacity to be activated by a diverse range of compounds, including fibrates and xenobiotics, known as peroxisome proliferators (Issemann and Green, 1990). In rodents the response to such activation is a proliferation and increase in size of peroxisomes in the liver. In turn this leads to a marked increase in the peroxisomal oxidation of fatty acids. Such peroxisome proliferation is ultimately associated with an increased incident of hepatocarcinoma (Lake, 1995). However, it has been subsequently found that such PPAR

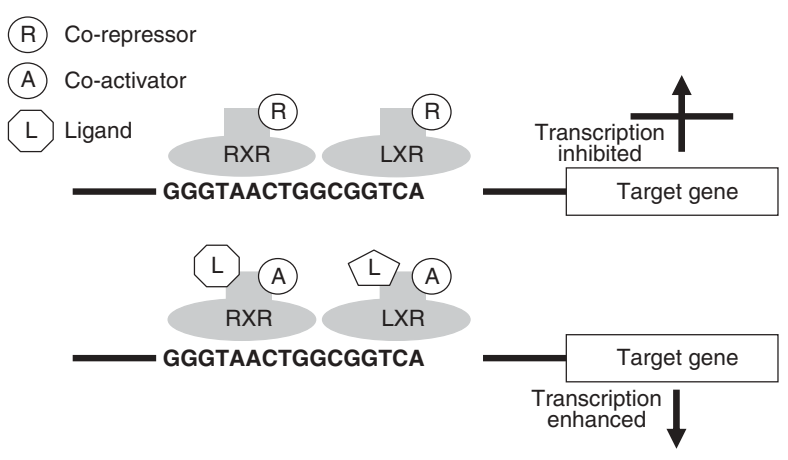

Figure 1 Regulation of gene transcription by LXR. LXR binds to the LXR response element of target genes as a heterodimer with RXR. When this dimer is bound in the absence of ligand, they may interact with co-repressors and gene transcription will be inhibited. When a ligand interacts with one or both of the receptors this will change their conformation, displacing co-repressors and attracting co-activators. As a result gene expression will be stimulated.

agonists do not induce peroxisome proliferation (or cancer) in a number of species including guinea pigs, primates and humans (Cattley et al., 1998; Choudhury et al., 2000). In fact, fibrates, known PPAR $\alpha$ ligands, have been commonly used in the treatment of elevated plasma lipids for many years (Watts and Dimmitt, 1999). The ligand activation of PPAR $\alpha$ is now known to be associated with transcriptional upregulation of a wide range of genes for proteins associated with fatty acid oxidation and lipoprotein metabolism, including acyl-CoA oxidase, carnitine palmitoyl transferase 1, lipoprotein lipase, apolipoproteins AI and CIII (Brown and Plutzky, 2007). A potential role for PPAR $\alpha$ in inhibiting the expression of genes for pro-inflammatory proteins (including vascular cell adhesion molecule-1, CX-1 and interleukin-6) in the vascular endothelium has received considerable attention (Marx et al., 2004).

PPAR $\gamma$ was originally identified as an important regulator of the aP2 gene, an adipocyte specific intracellular lipid binding protein (Tontonoz et al., 1994). It has now been established as an important regulator of adipocyte differentiation and regulator of adipose tissue metabolism. The insulin sensitising class of drugs commonly known as glitazones are agonists of PPARy (Lehman et al., 1995).

The least well characterised of the PPARs is PPAR $\beta$. Its ubiquitous expression suggests a fundamental role in regulating gene expression. It is most abundantly found in the small intestine, colon, heart, adipose tissue and brain (Brown and Plutzky, 2007).

A surprisingly diverse range of naturally occurring and synthetic compounds appear to act as ligands for the various PPAR isoforms. This includes both saturated and unsaturated fatty acids, though in general PUFA are more potent. All three PPAR subtypes have been shown to bind both n-3 and n-6 PUFA (Krey et al., 1997; Kliewer et al., 1997). In general, PUFA bind best to PPAR $\alpha$ followed by PPAR $\gamma$ and PPAR $\beta$ (Krey et al., 1997). Furthermore, a range of eicosanoids, derived form n-3 and n-6 PUFA, have also 
Salter and Tarling

been shown to be PPAR ligands, often with greater affinity than their parent molecules (Krey et al., 1997).

\section{Liver $X$ receptors}

LXRs function as sensors of cholesterol in the nucleus and they are activated by elevated levels of intracellular cholesterol in many different cell types. LXR $\alpha$ and LXR $\beta$ (also known as $\mathrm{NR} 1 \mathrm{H} 3$ and $\mathrm{NR} 1 \mathrm{H} 2$, respectively) were originally thought of as 'orphan' nuclear receptors as their natural ligands were not known. The naturally occurring oxysterols 22-R-hydroxycholesterol and 24,25-epoxycholesterol and long-chain fatty acids have since been identified as ligands for LXR (Janowski et al., 1999). LXR $\alpha$ is highly expressed in the liver but also at lower levels in adrenal glands, intestine, adipose, macrophages, kidney and lung whereas LXR $\beta$ is more ubiquitously expressed (Repa and Mangelsdorf, 2000). LXRs bind to response elements also as heterodimers with RXR. LXRs regulate the expression of genes involved in sterol and fatty acid metabolism, particularly hepatic bile acid synthesis. The rate-limiting enzyme in the synthesis of bile acids, $7 \alpha$ cholesterol hydroxylase (CYP7A) was one of the first genes to be identified as being directly regulated by LXRs (Peet et al., 1998). A whole range of genes involved in lipoprotein metabolism, including adenosine triphosphatebinding cassette protein $A 1$ (ABCA1, involved in reverse cholesterol transport), apolipoprotein $E$, lipoprotein lipase, cholesterol ester transfer protein and phospholipid transfer protein, have since been found to be regulated by LXRs (Geyeregger et al., 2006). LXRs also play an important role in the regulation of genes for proteins involved in other aspects of metabolism including lipogenesis (Peet et al., 1998) and carbohydrate metabolism (Cao et al., 2003; Laffitte et al., 2003). The role of LXR in regulating lipogenesis and its interaction with SREBP1C are discussed below.

\section{Hepatocyte nuclear factor $4 \alpha$}

HNF- $4 \alpha$ is another member of the nuclear receptor superfamily and, while as its name suggests it is highly expressed in liver, it is also found in kidney, intestine and pancreas (Sladek et al., 1990). As conventional gene knock-out is lethal, Hayhurst et al. (2001) addressed the role of HNF4 $\alpha$ in mature hepatocytes using a conditional gene knockout. Mice lacking hepatic HNF-4 $\alpha$ exhibit major perturbations of lipid metabolism with increased accumulation of lipid in the liver and reduced plasma cholesterol and triacylglycerol concentrations. This was associated with changes in expression of a range of genes involved in lipid and lipoprotein metabolism including apolipoproteins All, AIV, CII and $\mathrm{CIII}$, the microsomal triglyceride transfer protein and CYP7A1. HNF-4 $\alpha$ has been shown to bind long-chain fatty acyl CoA with high affinity (Hertz et al., 1998). Binding of saturated fatty acyl-CoAs activates HNF- $4 \alpha$ while unsaturated fatty acyl-CoAs inhibit HNF- $4 \alpha$ transcriptional activity. HNF- $4 \alpha$ binds to DR1 response elements as a homodimer and may potentially compete with PPAR/RXR heterodimers for DNA binding (Pégorier et al., 2004). It has also been shown that fibrates can be converted to CoA-thioesters that bind HNF- $4 \alpha$ to inhibit its transcriptional activity, thus providing another level of competition between HNF- $4 \alpha$ and PPARs (Hertz et al., 2001).

\section{Sterol regulatory element binding proteins}

The SREBPs play a major role in regulating the expression of genes associated with lipid and lipoprotein metabolism (Brown and Goldstein, 1999; Horton et al., 2002; Eberlé et al., 2004). They are membrane-bound members of the basic helix-loop-helix leucine zipper family of transcription factors. Two SREBP genes produce three separate proteins (SREBP1a and 1c from one and SREBP2 from the other). The SREBP1 and SREBP2 proteins share 47\% homology and SREBP1a and 1c differ in their first exon. SREBP1a and SREBP2 exhibit higher levels of transcriptional activation due to the presence of a longer transcriptional activator domain (Shimano et al., 1997). While in most cell lines SREBP2 and SREBP1a predominate, in most tissues, SREBP1c MRNA concentrations exceed those for SREBP1a (Shimomura et al., 1997a and 1997b). Each of the SREBP proteins is synthesised in an immature form which resides on the endoplasmic reticulum (ER). Activation is by a two-step proteolytic process that occurs in the Golgi apparatus (Brown and Goldstein, 1999; Figure 2a). SREBPs are transported to the Golgi through the action of an escort protein called SCAP (Goldstein et al., 2006). SCAP contains binding sites for COPII proteins which cluster the SCAP-SREBP complex into COPII-coated vesicles (Sun et al., 2005). These vesicles then bud from the ER and fuse with the Golgi. Increases in cellular cholesterol cause conformational changes in SCAP resulting in retention of SREBP in the ER (Nohturfft et al., 2000; Figure 2b). This has now been shown to be as a result of binding of SCAP to two ER anchor proteins called Insig 1 and 2 (Yang et al., 2002). The binding of Insig to SCAP inhibits its interaction with Copll proteins, and thus retards its movement to the Golgi (Goldstein et al., 2006). This leads to reduced proteolysis and a decrease in the nuclear active form of SREBP. This sensitivity to changes in intracellular sterol concentrations may not apply to all three SREBP isoforms. While evidence from studies using cell lines indicate that both SREBP1a and SREBP2 display such sensitivity to sterols, in vivo studies indicate SREBP1 may not respond to sterol depletion (Sheng et al., 1995).

The transcriptionally active SREBP translocates to the nucleus where it binds to sterol regulatory elements (SREs) on target genes. SRE nucleotide sequences vary considerably between genes but are commonly represented by the sequence $5^{\prime}$-TCACNCCAC-3' (Kim et al., 1995). While there is a sizeable overlap in the specificities of the individual SREBP isoforms, studies in transgenic mice overexpressing truncated nuclear active forms of SREBP in liver have shown specific roles for each isoform (Horton et al., 2002). Over-expression of SREBP2 results in a vast increase in cholesterol synthesis and SREBP2 has been shown to regulate at least 11 of the enzymes involved in the 
(a)

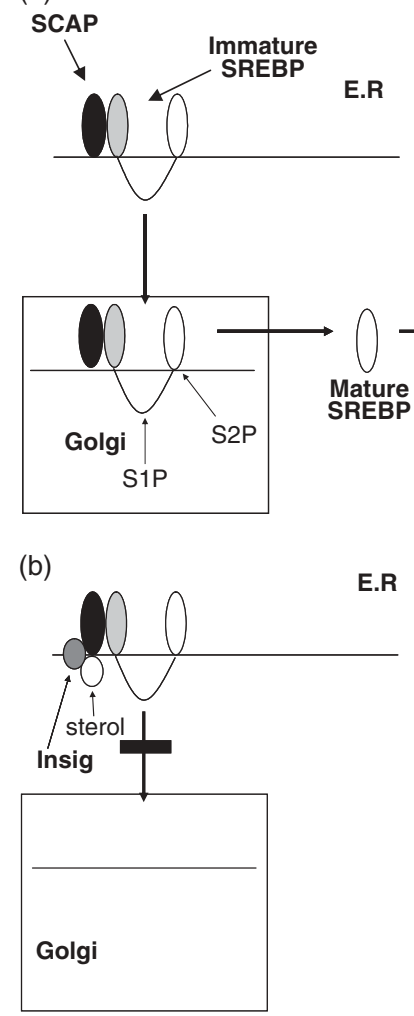

E.R

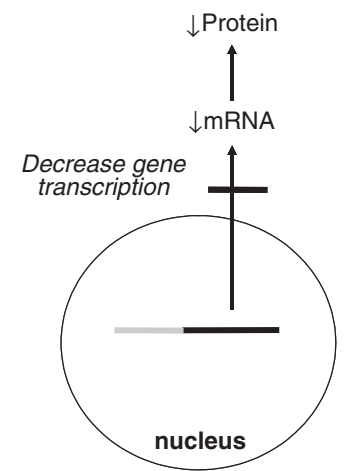

Figure 2 Regulation of gene transcription by SREBPs. Immature SREBP resides on the endoplasmic reticulum in association with SCAP. When cellular sterol concentrations are low (a) then SCAP escorts the SREBP to the Golgi apparatus where it is acted upon by two proteases (S1P and S2P) to release the active mature form of SREBP. This migrates to the nucleus where it interacts with the sterol regulatory element of target genes to upregulate gene transcription. In the presence of high cellular sterol concentrations, (b) the sterol interacts with the protein Insig which acts to anchor the SCAP-SREBP complex in the endoplasmic reticulum and thereby inhibit SREBP maturation. As a result the transcription of target genes is downregulated.

cholesterol synthetic pathway (Horton et al., 2000). Over-expressing the nuclear form of SREBP1a results in the accumulation of cholesterol and triglycerides in the liver (Shimano et al., 1996) while over-expressing SREBP1C causes an increase in liver triglycerides without a concomitant increase in cholesterol (Shimano et al., 1997). This suggests SREBP1C primarily regulates the expression of genes involved in fatty acid synthesis while SREBP1a can regulate enzymes of both the cholesterol and fatty acid synthetic pathways. SREBP1c mRNA and protein levels, and not those of SREBP2, are increased on a high carbohydrate diet or on re-feeding fasted mice, correlating with changes in lipogenic enzyme mRNA levels and dietary PUFA decrease nuclear SREBP-1 protein levels without affecting SREBP2 (Horton et al., 1998). SREBP2 expression is primarily regulated at a post-translational level, through modulation of cleavage of its membrane-bound precursor to release the active nuclear form, whereas SREBP1 expression is primarily regulated at the level of gene transcription (Horton et al., 2002; Eberlé et al., 2004).

\section{Regulation of gene expression by dietary lipids}

\section{Regulation of lipogenic gene expression by PUFA}

The ability for polyunsaturated fatty acids to downregulate the expression of genes for enzymes involved in fatty acid synthesis, including ACC, FAS and SCD, has been recognised for some time (Jump and Clarke, 1999; Sampath and Ntambi, 2005). These genes appear to be repressed by both $n-3$ and $n-6$ PUFA though response to the former may be more profound. More recently, there has been considerable interest in the ability of conjugated linoleic acids (CLA) to specifically reduce lipid deposition in adipose tissue (Wang and Jones, 2004). While at least part of these responses may be mediated by PUFA activation of PPAR $\alpha$ (see below), experiments in PPAR $\alpha$ knockout mice clearly indicate that PUFA still repress the expression of ACC and FAS (Ren et al., 1997). This has led to the search for alternative mechanisms.

The role of SREBP1C in regulating lipogenic gene expression makes it an obvious candidate for mediating the effects of PUFA on lipogenesis. Cell culture studies have clearly shown that PUFA have the ability to reduce SREBP1a and 1C mRNA and SREBP1 protein concentrations (Worgall et al., 1998). In our own experiments in the hamster feeding PUFA reduces mRNA for all three SREBPs in a manner that is dependent on the nature of the PUFA (Figure 3a). Docosahexaenoic acid (DHA, C22:6n-3) exerts a more potent effect than linoleic acid (C18:2n-6). Intriguingly, a mixture of $c-9, t-11$ and $t-10, c-12$ isomers of CLA appeared to actually increase SREBP1c mRNA concentrations. This effect of PUFA on SREBP mRNA concentrations has been attributed to both repression of gene transcription and increased turnover of the mRNA. To investigate further the impact of PUFA on SREBP1c gene transcription, we have recently cloned the human SREBP1c promoter (Tarling et al., 2004) and conducted a series of reporter gene experiments. The SREBP1c promoter was attached to a luciferase reporter gene and transfected into H4IIE rat hepatoma cells. Cells were then treated with various concentrations of PUFA. It can be seen that, again DHA showed a more potent repression of SREBP1c promoter activity compared linoleic acid. Interestingly, $c-9, t-11$ (but not $t-10, c-12$ ) CLA actually stimulated promoter activity at higher concentrations. Taken together these data provide further evidence that PUFA may directly regulate SREBP gene transcription and that the specific structure of the fatty acid impacts on its effects.

How does dietary PUFA regulate SREBP expression? Recent evidence suggests that, at least part of this effect may be mediated through LXR. PUFA have been reported to inhibit the interaction of oxysterols with LXR and thereby inhibit its activation of target genes, including SREBP1C itself (Hannah et al., 2001; Yoshikawa et al., 2001 and 2002). Both the mouse and the human SREBP1c promoters have been shown to contain potential LXREs (Tarling et al., 2004). Indeed, we have shown the increased activity of human SREBP1c promoter in the presence of a specific LXR agonist (E. J. Tarling et al., unpublished data). Thus, inhibition of the association of LXR with its oxysterol ligands by 

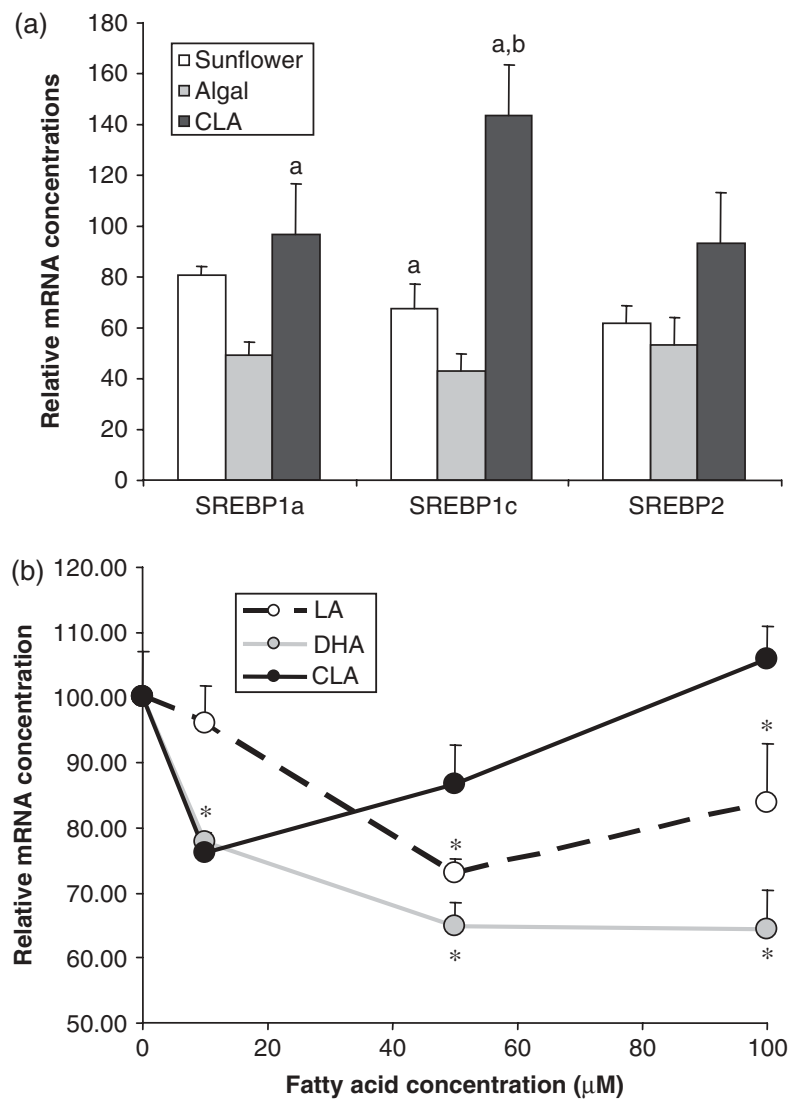

Figure 3 Effect of polyunsaturated fatty acids on SREBP expression. (a) Golden Syrian hamsters were fed chow supplemented with $0.12 \%$ cholesterol with or without $5 \%$ added fat for 4 weeks. Added fat included sunflower oil (rich in linoleic acid), algal oil (rich in DHA) or CLA (a mixture of approximately $50 \% c-9, t-11$ and $50 \% t-10, c-12$ isomers). At the end of the trial, RNA was extracted from liver and SREBP1a, 1c and 2 mRNA concentrations were determined by quantitative nuclease protection assay. Data are presented as a percentage of the mean mRNA concentration in animals fed chow + cholesterol without added fat (control). Compared with control animals, those fed sunflower oil showed no significant difference in mRNA concentration for any of the SREBPs, those fed algal oil had lower levels of mRNA for all three SREBPs and those fed CLA had higher levels SREBP1c mRNA $(P<0.05)$. Bars sharing common letters were significantly different from each other $(P<0.05)$ (S. Cooper et al., unpublished data). (b) The human SREBP1c promoter was cloned and inserted into a vector containing the firefly luciferase gene. This was then transfected into H4IIE (Rat hepatoma) cells which were then treated with the indicated quantities of fatty acids bound to albumin. Fatty acids included linoleic acid, DHA and $c-9, t-11 C L A$ isomer. SREBP1c promoter activity was assessed by determining the luciferase activity of the transfected cells. *Significantly different from cells incubated in the absence of added fatty acid (E. J. Tarling et al., unpublished data).

PUFA may repress activation of transcription of the SREBP1c gene by LXR. Another potential mechanism is the inhibition of LXR transcriptional activity by PUFA activation of PPARs. Over-expression of PPAR $\alpha$ and PPAR $\gamma$ in HEK-293 cells has been shown to inhibit SREBP1c promoter activity, and this effect was abolished by mutating the putative LXREs in the SREBP1c promoter (Yoshikawa et al., 2003). It has been suggested that this was a result of increased competition between PPAR and LXR for association with its transcriptional partner RXR. The downregulation of expression of
SREBP1a and SREBP2 we have observed in the hamster cannot as yet be explained by reduced LXR activity, as neither promoter have been reported to contain LXREs. Earlier work has suggested that PUFA may reduce SREBP mRNA stability as well as reducing gene transcription (Xu et al., 2001). There is also more recent data to suggest PUFA may affect the nuclear abundance of SREBP isoforms by regulating proteasomal degradation of these proteins (Botolin et al., 2006). Thus, it appears that the regulation of lipogenic gene expression by dietary PUFA is a result of a complex interaction between a number of transcription factors including SREBPS, PPARs and LXR.

\section{The hypotriglyceridemic effects of n-3 PUFA}

Long-chain n-3 PUFAs of marine origin have long been known to reduce plasma triacylglycerol concentrations (Harris, 1997). Despite extensive investigation the mechanisms underlying these effects remain to be fully elucidated (Davidson, 2006). Suppression of hepatic lipogenesis through reduced LXR-mediated transcription of SREBP1C, as described above, may certainly be one potential mechanism. Indeed, as can be seen in Figure 3a, DHA-rich algal oil appears to be considerably more effective at reducing hepatic SREBP1c mRNA concentrations than linoleic acid-rich sunflower oil. However, n-3 PUFA appear to exert effects on plasma triacylgycerol concentration even when subjects are consuming diets rich in fat and, presumably, when rates of hepatic lipogenesis are relatively low. The potential for these fatty acids, or their derivatives, to stimulate fatty acid oxidation through activation of hepatic PPAR $\alpha$ has long been suggested to represent another potential mechanism. As already discussed, fatty acids are ligands for the PPARs and in general n-3 PUFA are more potent activators of PPAR $\alpha$ than n- 6 PUFA. Feeding fish oil to rodents has been shown to increase the transcription of enzymes involved in fatty acid oxidation (Nakatani et al., 2003). However, PPAR $\alpha$-knockout mice still display a dose-dependent reduction in plasma triacylglycerol in response to fish oil, suggesting that PPAR $\alpha$ has only a minor role in this response (Dallongeville et al., 2001). It has also been suggested that n-3 PUFA may have effects on the activity of HNF- $4 \alpha$ and this may be responsible for some of the hypotriglyceridemic effects of these fatty acids (Davidson, 2006).

\section{Regulation of gene expression by saturated fatty acids} Evidence of direct regulation of gene expression by saturated fatty acids is considerably less compelling. Saturated fatty acids profoundly influence the activity of a range of proteins involved in lipid and lipoprotein metabolism. However, in many cases this may be an indirect effect. For example, diets rich in saturated fatty acids may alter the concentrations of cholesterol and its derivatives in the liver (Spady et al., 1993). Saturated fatty acids have been reported to suppress the esterification of cholesterol in the liver, thereby leading to an accumulation of metabolically active free cholesterol or 
perhaps oxygenated derivatives (Spady et al., 1993). This effect is specific to saturated fatty acids with 12-16 carbon atoms, with shorter chain fatty acids and stearic acid (C18:0) having no effect (Woollett et al., 1992). These may then regulate gene expression through modulating the activity of SREBPS or LXR. This has been suggested to be a potential mechanism through which saturated fatty acids reduce LDL receptor expression and thereby increase plasma LDL cholesterol concentrations (Spady et al., 1993).

One mechanism whereby saturated fatty acids may have a direct effect on gene expression is through modulating the activity of HNF- $4 \alpha$. As described above, there is evidence to suggest that saturated fatty acid, as coenzyme A derivatives, may modulate HNF- $4 \alpha$ - regulation of gene expression (Hertz et al., 1998). However, direct evidence of dietary fatty acids acting through such a mechanism is still lacking.

It has recently been reported that a diet rich in saturated fat increased expression of the transcriptional co-activator PGC1 $\beta$ (Lin et al., 2005). This in turn was shown to enhance the transcriptional activity of SREBP1c. Modulation of the activity of co-activators, or indeed co-repressors by dietary lipids, opens up another intriguing level of nutrient:gene interaction.

\section{Conclusions}

It is clear that dietary lipids have the potential to modulate metabolism through altering the expression of genes for key proteins. The discussion above outlines growing evidence for potential mechanisms whereby they may exert such effects. However, much of this evidence emerges from cell culture studies where single fatty acid entities can be added and effects measured or animal experiments where diets of clearly defined fatty acid composition have been used. Translating these results into a situation when complex mixtures of fatty acids are normally consumed and join the already multifarious mixture of fatty acids and their derivatives already present in the body, represents a major challenge for future research.

\section{References}

Botolin D, Wang Y, Christian B and Jump DB 2006. Docosahexaenoic acid $(22: 6, n-3)$ regulates rat hepatocyte SREBP-1 nuclear abundance by Erk- and $26 \mathrm{~S}$ proteasome-dependent pathways. Journal of Lipid Research 47, 181-192. Brown JD and Plutzky J 2007. Peroxisome proliferator-activated receptors as transcriptional nodal points and therapeutic targets. Circulation 115, 518-533. Brown MS and Goldstein JL 1999. A proteolytic pathway that controls the cholesterol content of membranes, cells and blood. Proceedings of the National Academy of Sciences, USA 96, 11041-11048.

Cao G, Liang Y, Broderick CL, Oldham BA, Beyer TP, Cao G, Liang Y, Broderick CL, Oldham BA, Beyer TP, Schmidt RJ, Zhang Y, Stayrook KR, Suen C, Otto KA, Miller AR, Dai J, Foxworthy P, Gao H, Ryan TP, Jiang XC, Burris TP, Eacho PI and Etgen $\mathrm{GI} 2003$. Antidiabetic action of a liver $X$ receptor agonist mediated by inhibition of hepatic gluconeogenesis. The Journal of Biological Chemistry 278, 1131-1136.

Cattley RC, DeLuca J, Elcombe C, Fenner-Crisp P, Lake BG, Marsman DS, Pastoor TA, Popp JA, Robinson DE, Schwetz B, Tugwood J and Whali W 1998.
Do peroxisome proliferating compounds pose a hepatocarcinogenic hazard to humans? Regulatory Toxicology and Pharmacology 27, 47-60.

Choudhury Al, Chahal S, Bell AR, Tomlinson SR, Roberts RA, Salter AM and Bell DR 2000. Species differences in peroxisome proliferation; mechanisms and relevance. Mutation Research 448, 201-212.

Dallongeville J, Bauge E, Tailleux A, Peters JM, Gonzalez FJ, Fruchart J-C and Staels B 2001. Peroxisome proliferator-activated receptor $\alpha$ is not rate-limiting for the lipoprotein-lowering action of fish oil. The Journal of Biological Chemistry 276, 4634-4639.

Davidson MH 2006. Mechanisms for the hypotriglyceridemic effect of marine omega-3 fatty acids. The American Journal of Cardiology 98, 27i-33i.

Deckelbaum RJ, Worgall TS and Seo T 2006. n-3 fatty acids and gene expression. The American Journal of Clinical Nutrition 83, 1520S-1525S.

Desvergne B and Wahli W 1999. Peroxisome proliferators-activated receptors: nuclear control of metabolism. Endocrine Reviews 20, 649-688.

Eberlé $D$, Hegarty $B$, Bossard $P$, Ferré $P$ and Foufelle $F$ 2004. SREBP transcription factors: master regulators of lipid homeostasis. Biochimie 86, 839-848.

Geyeregger R, Zeyda M and Stulnig TM 2006. Liver X receptors in cardiovascular and metabolic disease. Cellular and Molecular Life Sciences 63, 524-539.

Glass CK and Rosenfeld MG 2000. The coregulator exchange in transcriptional functions of nuclear receptors. Genes and Development 14, 121-141.

Goldstein JL, DeBose-Boyd RA and Brown MS 2006. Protein sensors for membrane sterols. Cell 124, 35-46.

Hannah VC, Ou J, Luong A, Goldstein JL and Brown MS 2001. Unsaturated fatty acids downregulate SREBP isoforms $1 \mathrm{a}$ and $1 \mathrm{c}$ by two mechanisms. The Journal of Biological Chemistry 276, 4365-4372.

Harris WS 1997. n-3 fatty acids and serum lipoproteins: human studies. The American Journal of Clinical Nutrition 65, 1645S-1654S.

Hayhurst GP, Lee Y-H, Lambert G, Ward JM and Gonzalez FJ 2001. Hepatocyte nuclear factor $4 \alpha$ (nuclear receptor 2A1) is essential for maintenance of hepatic gene expression and lipid homeostasis. Molecular and Cellular Biology 21, 1393-1403.

Hertz R, Magenheim J, Berman I and Bar-Tana J 1998. Fatty acyl CoA thioesters are ligands of hepatic nuclear factor $4 \alpha$. Nature 392, 512-515.

Hertz R, Sheena V, Kalderon B, Berman I and Bar-Tana J 2001. Suppression of hepatic nuclear factor 4-alpha by acyl-CoA thioesters of hypolipidemic peroxisome proliferators. Biochemical Pharmacology 61, 1057-1062.

Horton JD, Bashmakov Y, Shimomura I and Shimano HC 1998. Regulation of sterol regulatory element binding proteins in livers of fasted and refed mice. Proceedings of the National Academy of Science, USA 95, 5987-5992.

Horton JD, Shimomura I, Brown MS, Hammer RE, Goldstein JL and Shimano N 2000. Activation of cholesterol synthesis in preference to fatty acid synthesis in liver and adipose tissue of transgenic mice overproducing sterol regulatory element-binding protein-2. The Journal of Clinical Investigation 101, 2331-2339.

Horton JD, Goldstein JL and Brown MS 2002. SREBPs: activators of the complete programme of cholesterol and fatty acid synthesis in the liver. The Journal of Clinical Investigation 109, 1125-1131.

Issemann I and Green S 1990. Activation of a member of the steroid hormone receptor superfamily by peroxisome proliferators. Nature 347, 645-650.

Janowski BA, Grogan MJ, Jones SA, Wisely GB, Kliewer SA, Corey EJ and Mangelsdorf DJ 1999. Structural requirements of ligands for the oxysterol liver $X$ receptors, $L X R \alpha$ and $L X R \beta$. Proceedings of the National Academy of Sciences 96, 266-271.

Jump DB and Clarke SD 1999. Regulation of gene expression by dietary fat. Annual Reviews of Nutrition 19, 63-90.

Jump DB, Botolin D, Wang Y, Xu J, Christian B and Demeure 0 2005. Fatty acid regulation of hepatic gene transcription. The Journal of Nutrition 135, 2503-2506. Kalant D and Cianflone K 2004. Regulation of fatty acid transport. Current Opinion in Lipidology 15, 309-314.

Katan MB, Zock PL and Mensink RP 1994. Effects of fats and fatty acids on blood lipids in humans: an overview. American Journal of Clinical Nutrition 60, 1017S-1022S.

Kim JB, Spotts GD, Halvorsen YD, Shih HM, Ellenberger T, Towle HC and Spiegelman BM 1995. Dual DNA binding specificity of ADD1/SREBP1 controlled by a single amino acid in the basic helix-loop-helix domain. Molecular and Cellular Biology 15, 2582-2588. 
Kliewer SA, Sundeth SS, Jones SA, Brown PJ, Wisely GB, Koble CS, Devchand P, Whali W, Willson TM and Lenhard JM 1997. Fatty acids and eicosanoids regulate gene expression through direct interactions with peroxisome proliferator-activated receptors $\alpha$ and $\beta$. Proceedings of the National Academy of Science, USA 94, 4318-4323.

Krey G, Braissant O, L'Horset F, Kalkhoven E, Perroud M, Parker MG and Whali W 1997. Fatty acids, eicosanoids, and hypolipidemic agents identified as ligands of peroxisome proliferator-activated receptors by coactivator-dependent receptor ligand assay. Molecular Endocrinology (Baltimore, MD) 11, 779-791.

Laffitte BA, Chao LC, Li J, Walczak R, Hummasti S, Joseph SB, Castrillo A, Wilpitz DC, Mangelsdorf DJ, Collins JL, Saez E and Tontonoz P 2003. Activation of liver $X$ receptor improves glucose tolerance through coordinate regulation of glucose metabolism in liver and adipose tissue. Proceedings of the National Academy of Science, USA 100, 5419-5424.

Lake BG 1995. Mechanisms of hepatocarcinogenicity of peroxisomeproliferating drugs and chemicals. Annual Reviews of Pharmacology and Toxicology 35, 483-507.

Lehman JM, Moore LB, Smith-Oliver TA, Wilkinson WO, Willson TM and Kliewer SA 1995. An antidiabetic thiazolidinedione is a high affinity ligand for peroxisome proliferator-activated receptor gamma (PPAR gamma). The Journal of Biological Chemistry 270, 12953-12956.

Lin J, Yang R, Tarr PT, Wu PH, Handschin C, Li S, Yang W, Pei L, Uldry M, Tontonoz P, Newgard CB and Spiegelman BM 2005. Hyperlipidemic effects of dietary saturated fats mediated through PGC-1 beta coactivation of SREBP. Cell 120, 261-273.

Marx N, Duez H, Fruchart JC and Staels B 2004. Peroxisome proliferatoractivated receptors and atherogenesis: regulators of gene expression in vascular cells. Circulation Research 94, 1168-1178.

Nakatani T, Kim H-J, Kaburagi Y, Yasuda K and Ezaki 0 2003. A low fish oil inhibits SREBP-1 proteolytic cascade, while high-fish-oil feeding decreases SREBP-1 mRNA in mice liver: relationship to anti-obesity. Journal of Lipid Research 44, 369-379.

Nohturfft A, Yabe D, Goldstein JL, Brown MS and Espenshade PJ 2000. Regulated step in cholesterol feedback localized to budding of SCAP from ER membranes. Cell 102, 315-323.

Peet DJ, Turley SD, Ma W, Janowski BA, Lobaccaro J-MA, Hammer RE and Mangelsdorf DJ 1998. Cholesterol and bile acid metabolism are impaired in mice lacking the nuclear oxysterol receptor LXR $\alpha$. Cell 93, 693-704.

Pégorier J-P, Le May C and Girard J 2004. Control of gene expression by fatty acids. The Journal of Nutrition 134, 2444S-2449S.

Ren B, Thelen AP, Peters JM, Gonzalez FJ and Jump DB 1997. Polyunsaturated fatty acid suppression of hepatic fatty acid synthase and 514 gene expression does not require peroxisome proliferator - activated receptor alpha. Journal of Biological Chemistry 272, 26382-26827.

Repa JJ and Mangelsdorf DJ 2000. The role of orphan nuclear receptors in the regulation of cholesterol homeostasis. Annual Reviews of Cell and Developmental Biology 16, 459-481.

Robinson-Rechavi M, Carpentier AS, Duffraisse M and Laudet V 2001. How many nuclear receptors are there in the human genome? Trends in Genetics 17, 554-556.

Sampath $\mathrm{H}$ and Ntambi J 2005. Polyunsaturated fatty acid regulation of genes of lipid metabolism. Annual Reviews of Nutrition 25, 317-340.

Sheng Z, Otani H, Brown MS and Goldstein JL 1995. Independent regulation of sterol regulatory element-binding proteins 1 and 2 in hamster liver. Proceedings of the National Academy of Science, USA 92, 935-938.

Shimano H, Horton JD, Hammer RE, Shimomura I, Brown MS and Goldstein JL 1996. Overproduction of cholesterol and fatty acids causes massive liver enlargement in transgenic mice expressing truncated SREBP-1a. The Journal of Clinical Investigation 98, 1575-1584.

Shimano H, Horton JD, Shimomura I, Hammer RE, Brown MS and Goldstein JL 1997. Isoform 1c of sterol regulatory element binding protein is less active than isoform 1a in livers of transgenic mice and in cultured cells. The Journal of Clinical Investigation 99, 846-854.

Shimomura I, Shimano H, Horton JD, Goldstein JL and Brown MS 1997a. Differential expression of exons $1 \mathrm{a}$ and $1 \mathrm{c}$ in mRNAs for sterol regulatory element binding protein-1 in human and mouse organs and cultured cells. The Journal of Clinical Investigation 99, 838-845.

Shimomura I, Bashmakov Y, Shimano H, Horton JD, Goldstein JL and Brown MS 1997b. Cholesterol feeding reduces nuclear forms of sterol regulatory element binding proteins in hamster liver. Proceedings of the National Academy of Science, USA 94, 12354-12359.

Sladek FM, Zhong W, Lai E and Darnell JE 1990. Liver-enriched transcription factor HNF4 is a novel member of the steroid hormone receptor superfamily. Genes and Development 4, 2353-2365.

Spady DK, Woollett LA and Dietschy JM 1993. Regulation of plasma LDLcholesterol levels by dietary cholesterol and fatty acids. Annual Reviews in Nutrition 13, 355-381.

Sun L-P, Li L, Goldstein JL and Brown MS 2005. Insig required for sterolmediated inhibition of Scap/SREBP binding to COPII proteins in vitro. Journal of Biological Chemistry 280, 26483-26490.

Tarling E, Salter A and Bennett A 2004. Transcriptional regulation of human SREBP-1c (sterol-regulatory-element-binding protein-1c): a key regulator of lipogenesis. Biochemical Society Transactions 32, 107-109.

Tontonoz P, Hu E, Graves RA, Budavari Al and Spiegelman BM 1994. mPPAR gamma 2: tissue-specific regulator of an adipocyte enhancer. Genes and Development 8, 1224-1234.

Wang $Y$ and Jones PJ 2004. Dietary conjugated linoleic acid and body composition. The American Journal of Clinical Nutrition 79, 1153S-1158S.

Watts GF and Dimmitt SB 1999. Fibrates, dyslipoproteinaemia and cardiovascular disease. Current Opinion in Lipidology 10, 561-574.

Wolfrum C, Borrmann CM, Borchers T and Spener F 2001. Fatty acids and hypolipidemic drugs regulate peroxisome proliferator-activated receptors $\alpha$ and $\gamma$-mediated gene expression via liver fatty acid binding protein: a signalling path to the nucleus. Proceedings of the National Academy of Sciences 98, 2323-2328.

Woollett LA, Spady DK and Dietschy JM 1992. Regulatory effects of the saturated fatty acids 6:0 through 18:0 on hepatic low density lipoprotein receptor activity in the hamster. The Journal of Clinical Investigation 89, 1133-1141.

Worgall TS, Sturley SL, Soe T, Osborne TF and Deckelbaum RJ 1998. Polyunsaturated fatty acids decrease expression of promoters with sterol regulatory elements by decreasing levels of sterol regulatory element binding protein. Journal of Biological Chemistry 273, 23537-23540.

Xu J, Teran-Garcia M, Park JH, Nakamura MT and Clarke SD 2001. PUFA suppress hepatic SREBP-1 expression by accelerating transcript decay. Journal of Biological Chemistry 276, 9800-9807.

Yang T, Espenshade PJ, Wright ME, Yabe D, Gong Y, Aebersold R, Goldstein JL and Brown MS 2002. Crucial step in cholesterol homeostasis: sterols promote binding of SCAP to INSIG-1, a membrane protein that facilitates retention of SREBPs to the ER. Cell 110, 489-500.

Yoshikawa T, Shimano H, Amemiya-Kudo M, Yahagi N, Hasty AH, Matsuzaka T, Okazaki H, Tamura Y, lizuka Y, Ohashi K, Osuga J, Harada K, Gotoda T, Kimura S, Ishibashi $S$ and Yamada N 2001. Identification of liver $X$ receptorretinoid $X$ receptor as an activator of the sterol regulatory elementbinding protein 1c gene promoter. Molecular and Cellular Biology 21, 2991-3000.

Yoshikawa T, Shimano $H$, Yahagi N, Ide T, Amemiya-Kudo M, Matsuzaka T, Nakakuki M, Tomita S, Okazaki H, Tamura Y, lizuka Y, Ohashi K, Takahashi A, Sone H, Osuga JiJ, Gotoda T, Ishibashi S and Yamada N 2002. Polyunsaturated fatty acids suppress sterol regulatory element-binding protein 1c promoter activity by inhibition of liver $X$ receptor (LXR) binding to $L X R$ response elements. Journal of Biological Chemistry 277, 1705-1711.

Yoshikawa T, Ide T, Shimano H, Yahagi N, Amemiya-Kudo M, Matsuzaka T, Yatoh S, Kitamine T, Okazaki H, Tamura Y, Sekiya M, Takahashi A, Hasty AH, Sato R, Sone H, Osuga J, Ishibashi S and Yamada N 2003. Cross-talk between peroxisome proliferator-activated receptor (PPAR) alpha and liver $X$ receptor (LXR) in nutritional regulation of fatty acid metabolism. I. PPARs suppress sterol regulatory element binding protein-1c promoter through inhibition of LXR signalling. Molecular Endocrinology 17, 1240-1254. 